\title{
DIPLOMASI SOFT POWER ASIMETRIS BERBASIS SUMBER DAYA KELAUTAN LINTAS BATAS DALAM PENYELESAIAN SENGKETA LAUT CINA SELATAN
}

\author{
Tahegga Primananda Alfath, Riyo Lian Nugroho \\ Fakultas Hukum Universitas Narotama Surabaya \\ J1. Arief Rachman Hakim 51, Sukolilo, Surabaya \\ Email: tahegga.primananda@narotama.ac.id, ryolian@ymail.com
}

\begin{abstract}
South China Sea (SCS) conflict starting from the issuance of new maps by People's Republic of Tiongkok in 1947, mostly claim SCS territory to bring imaginary line called the nine dash line that is based on the historical aspect. Under the UNCLOS, a claim over a territory that is based on stale Historical not justified. The nine-dash line where tensions among countries in the Neighborhood SCS, including Indonesia. There are several peaceful dispute settlement mechanism of UNCLOS including conciliation, binding settlement, arbitration, special arbitration. SCS dispute settlement should use the methods of peaceful settlement that called diplomatic winwin solution. Asymmetric soft power diplomacy that takes into account the interests of both countries and organizations will be able to be an alternative dispute resolution SCS protracted, with a record of win-win solution can be felt directly to their dispute. The method used is using the method with the approach of the Statute Law Research Approach and Conceptual Approach, supported by Legal Materials Primary and Secondary Legal Materials.
\end{abstract}

Keywords: South China Sea Conflict, Nine-Dash Line, Asymmetric Soft Power Diplomacy

\begin{abstract}
Abstrak
Konflik Laut Cina Selatan (LCS) yang berlarut berawal dari diterbitkanya peta baru oleh Republik Rakyat Tiongkok pada tahun 1947 yang sebagian besar mengklaim wilayah LCS, hingga terdapat garis imajiner yang disebut nine dash line yang didasarkan dari aspek historis. Berdasarkan pada UNCLOS, klaim atas suatu wilayah yang didasarkan dari apek Historis tidak dibenarkan. keberadaan nine dash line tersebut menimbulkan ketegangan antar negara di sekitar LCS, termasuk Indonesia. Terdapat beberapa mekanisme penyelesaian sengketa damai dalam UNCLOS diantarannya konsiliasi, penyelesaian mengikat, arbitrase, arbitrase khusus. Penyelesaian sengketa LCS harus menggunakan metode penyelesaian secara damai. Yakni dengan diplomasi yang win-win solution atau tidak saling merugikan. Diplomasi soft power asimetris yang memperhatikan kepentingan-kepentingan baik negara maupun organisasi nantinya mampu menjadi alternatif penyelesaian sengketa LCS yang berlarut-larut, dengan catatan win-win solution dapat dirasakan secara langsung bagi mereka yang bersengketa. Metode penelitian yang digunakan adalah menggunakan Metode Penelitian Hukum dengan pendekatan Statute Approach dan Conceptual Approach yang ditunjang dengan Bahan Hukum Primer dan Bahan Hukum Sekunder.
\end{abstract}

Kata Kunci: Konflik Laut Cina Selatan, Nine-Dash Line, Diplomasi Soft Powers Asimetris 


\section{A. Pendahuluan}

Sir Walter Raleigh seorang penulis, penyair serta penjelajah berkebangsaan Inggris di awal abad ke-17 mengatakan, "whoever commands the sea, commands the trade, whoever commands the trade of the world commands the riches of the world"1. Siapa yang menguasai laut maka ia yang menguasai dunia, hal tersebut yang selalu di dengung dengungkan oleh para petinggi negara, pelaut, dan para prajurit angkatan laut di seluruh dunia. Hal tersebut juga disampaikan oleh Kepala Staf Angkatan Laut (KASAL), dalam kata sambutan dalam buku Dewaruci, Pelayaran Pertama Menaklukan Tujuh Samudra ${ }^{2}$. Dari pernyataan tersebut dapat dikatakan semua negara saling memperebutkan kekuasaan dalam bidang laut agar dapat menguasai dunia.

Dewasa ini banyak terjadi permasalaahan di bidang kelautan, salah satu contohnya adalah konflik di Laut Cina Selatan (LCS), LCS merupakan laut yang luasnya 3,5 juta kilometer persegi. Luas itu 39 persen dari total luas wilayah laut di Asia Tenggara yang berjumlah kurang lebih 8,9 juta kilometer persegi. Bila dibandingkan dengan total laut dunia, luas LCS sekitar 2,5 persennya. Secara geografis LCS terbentang dari arah barat daya ke timur laut, batas selatan $3^{\circ}$ Lintang Selatan antara Sumatera Selatan dan Kalimantan (Selat Karimata), dan batas utara-nya adalah Selat Taiwan dari ujung utara Taiwan ke pesisir Fujian di Tiongkok daratan. LCS terletak disebelah selatan Republik Rakyat Tiongkok (RRT) dan Taiwan, di sebelah Barat Filipina, di sebelah barat Laut Sabah (Malaysia), Sarawak (Malaysia), dan Brunei, di sebelah utara Indonesia, di sebelah timur laut Semenanjung Malaya (Malaysia) dan Singapura, dan disebelah timur Vietnam ${ }^{3}$. LCS tergolong laut setengah tertutup atau semi-closed sea $^{4}$ yang 90 persen diantaranya dilingkari oleh daratan dan pulaupulau. Di tengah-tengah LCS, terdapat dua kepulauan yang menjadi perselisihan antar pihak yang mengelilinginya, yaitu Kepulauan Spratly dan Kepulauan Paracel. Dua kepulauan itu tak pernah tercatat dihuni secara tetap oleh manusia karena kebanyakan hanya berupa karangkarang kecil ${ }^{5}$.

\section{Gambar 1. Peta LCS dan Negara yang berkonflik}

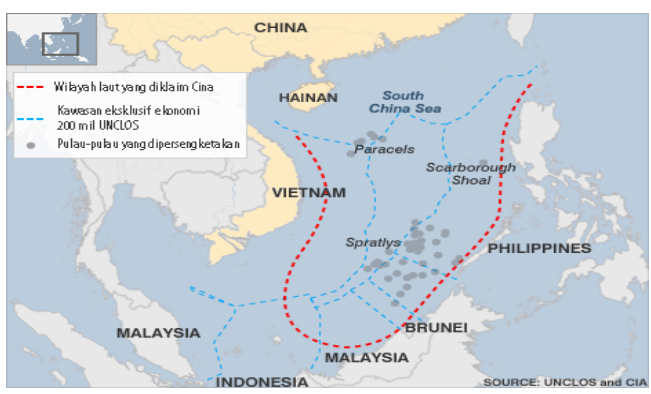

1 http://www.tnial.mil.id/tabid/79/articleType/ArticleView/articleId/16930/Default.aspx diakses pada 28 November 2015

2 Cornelis Kowaas, Dewaruci: Pelayaran Pertama Menaklukan Tujuh Samudra, kompass, Jakarta, 2010 www.anneahira.com/laut-cina-selatan.htm 1, diakses pada tanggal 28 November 2015

4 Definisi semi-closed sea menurut UNCLOS 1982, merupakan suatu teluk, lembah laut, atau yang dikelilingi oleh dua atau lebih negara, yang dihubungkan dengan laut lainya atau samudera oleh suatu alur yang sempit atau yang terdiri seluruhnya atau terutama dari laut teritorial \& zona ekonomi eksklusif dua atau lebih negara pantai

5 Syamsumar Dam, Politik Kelautan Jakarta, Bumi Aksara, Jakarta, 2010, hlm. 242. 
Dalam konflik LCS melibatkan beberapa negara Association of South East Asia yang selanjutnya disebut ASEAN, yaitu Filipina, Vietnam, Brunei Darussalam, dan Malaysia yang bersitegang dengan Tiongkok dan Taiwan yang saling mengklaim atas gugusan pulau tersebut $^{6}$. Kawasan LCS merupakan jalur strategis pelayaran yang padat dan sibuk, Posisinya sangat signifikan dalam hal pelayaran internasional. Lebih dari 40.000 ribu kapal melewati jalur LCS setiap tahunnya, setelah melewati jalur Selat Malaka ${ }^{7}$ banyak kapal perniagaan yang melewati jalur di sepanjang LCS juga dikenal sebagai jalur pelayaran penting. Jalur pelayaran ini seringkali disebut maritime superhighway karena merupakan salah satu jalur pelayaran internasional paling sibuk di dunia. Lebih dari setengah lalu lintas supertanker dunia berlayar melalui jalur ini, lewat Selat Malaka, Sunda dan Lombok. Jumlah supertanker yang berlayar melewati Selat Malaka dan bagian barat daya LCS bahkan lebih dari tiga kali yang melewati Terusan Suez dan lebih dari lima kali lipatnya Terusan Panama ${ }^{8}$.

Menurut data dari The Geology and Mineral Resources Ministry of the People's Republic of China (RRC) memperkirakan bahwa kandungan minyak yang terdapat di kepulauan Spartly adalah sekitar 17,7 miliar ton $(1,60 \times 1010 \mathrm{~kg})$. Fakta tersebut menempatkan kepulauan Spartly ${ }^{9}$ sebagai tempat cadangan minyak terbesar keempat di dunia ${ }^{10}$ Dari segi kekayaan ikan, LCS menyumbang 10 persen dari total penangkapan ikan di seluruh dunia dan menjadi sumber protein penting bagi 600 juta orang yang hidup di sekitarnya. Dari segi kekayaan ekologi, terdapat 51 jenis bakau dan 450 spesies karang di LCS yang dicatat oleh Filipina ${ }^{11}$

Isu yang berkembang mengenai pembangunan oleh Tiongkok yang mereka sebut nine dash line atau sembilan garis putus-putus yang yang memanjang ke jantung maritim Asia Tenggara. Vietnam, Filipina, Taiwan, Malaysia dan Brunei ${ }^{12}$. proyek reklamasi di pulau yang berada di salah satu titik di LCS, memicu ketegangan dengan beberapa negara. Landasan terbang dan fasilitas komunikasi terus dibangun dan diyakini akan dipakai sebagai pangkalan militer. hal tersebut yang menjadi urgensi bagi kedaulatan Indonesia, banyak media baik nasional maupun internasional memberitakan akan dampak dari nine dash line yang dilakukan oleh Tiongkok akan berimbas pada kepulauan Natuna yang merupakan wilayah kedaulatan Indonesia. Upaya tegas dilakukan oleh Indonesia dengan cara secara konsisten menegakkan

6 http://internasional.metrotvnews.com/read/2015/10/30/185779/tiongkok-as-didesak-atasi-klaim-laut-chinaselatan-di-p diakses pada 28 November 2015

Bambang Cipto, Hubungan Internasional di Asia Tenggara, Pustaka Pelajar, Yogyakarta, 2007, hlm. 205

8 Simela Victor Muhammad (Kepentingan China dan Posisi ASEAN dalam Sengketa Laut China Selatan : Info Singkat Hubungan Internasional Vol. IV No. 08/II/P3DI/April /2012) Hal. 6.

9 Sementara ini kepulauan Spratly di klaim oleh beberapa negara antara lain, Tiongkok, Brunai, Filipina, Malaysia, Vietnam. Sumber : Republika.co.id/Pakar hukum laut jelaskan posisi Indonesia dalam sengketa Spratly. Diakses tanggal 14 Februari 2016

10 http://militaryanalysisonline.blogspot.com/2013/09/sengketa-kepulauan-spratly-potensi.html, diakses tanggal 28 November 2015

11 Gao Zhiguo, "South China Sea: Turning Suspicion into Mutual Understanding and Cooperation", dalam SawSwee-Hock, Sheng Lijun, dan Chin Kin Wah (eds.), ASEAN-China Relations: Realities and Prospects (Singapura:ISEAS Publishing, 2005), h. 330.dalam http://etd.repository.ugm.ac.id/index.php?mod=download $\&$ sub=DownloadFile \&act=view \& typ=html\&id=64604\&ftyp=potongan\&potongan=S1-2013-272952-

chapter1.pdf diakses pada 28 November 2015

12 http://nationalgeographic.co.id/berita/2015/11/indonesia-minta-china-klarifikasi-atas-klaim-kepulauan-natuna diakses pada 29 November 2015 
bahwa Tiongkok dan Indonesia harus menemukan mekanisme resolusi yang sesuai melalui negosiasi-negosiasi langsung dan konsultasi, dengan menghormati hukum internasional dan berbasis pada fakta sejarah. ${ }^{13}$

Upaya penyelesaian sengketa di LCS, telah banyak dilakukan demi terselesaikanya perselisihan tersebut oleh ASEAN, dari mulai Konferensi Tingkat Tinggi ASEAN, ForumForum Khusus yang mempertemukan negara-negara yang bersengketa didalamnya, Gugatan ke Mahkamah Internasional oleh negara yang bersengketa. Hingga dewasa ini terdengar upaya akan pengimplementasian sebuah dokumen yang isinya mengenai hubungan ASEAN dan Tiongkok, terhadap LCS pada tahun 2002, Declaration on the Conduct of Parties in the South Cina Sea (DOC), karena dalam upaya tersebut dirasa belum berhasil memenuhi misi untuk membangun rasa saling percaya di antara negara-negara yang terlibat di dalam konflik LCS dan untuk mencegah konflik LCS berkembang lebih jauh. Maka upaya yang masih terus dibahas adalah menegosiasikan Code of Conduct $(\mathrm{CoC})^{14}$, atau etika berhubungan, LCS. Yang terus diupayakan agar tewujudnya harapan akan terselesainya perselisihan antar negera di LCS.

\section{Tabel 1}

\section{Upaya Penyelesaian Sengketa LCS}

\begin{tabular}{|c|c|c|c|}
\hline No & Upaya & Substansi & Hasil \\
\hline 1. & $\begin{array}{c}\text { ASEAN } \\
\text { Declaration on the } \\
\text { South China Sea } \\
1992\end{array}$ & $\begin{array}{c}\text { Deklarasi ini merupakan bentuk solidaritas } \\
\text { ASEAN, dengan Pendekatan Kostruktif dalam } \\
\text { Penyelesaian Konflik }\end{array}$ & $\begin{array}{l}\text { Belum mampu } \\
\text { menyelesaikan } \\
\text { sengketa }\end{array}$ \\
\hline 2. & $\begin{array}{c}\text { Konferensi } \\
\text { Tingkat Tinggi } \\
\text { ASEAN }\end{array}$ & $\begin{array}{c}\text { Menyambut baik ditandatanganinya DOC dan } \\
\text { mengharapkan segera dibentuk COC }\end{array}$ & $\begin{array}{c}\text { Belum mampu } \\
\text { menyelesaikan } \\
\text { sengketa }\end{array}$ \\
\hline 3. & $\begin{array}{c}\text { ASEAN Regional } \\
\text { Forum }(\text { ARF })\end{array}$ & $\begin{array}{c}\text { Mendorong saling percaya, melalui transparasi } \\
\text { dan mencegah kemungkinan timbulnya } \\
\text { ketegangan maupun konflik di kawasan Asia } \\
\text { Pasifik }\end{array}$ & $\begin{array}{c}\text { Belum mampu } \\
\text { menyelesaikan } \\
\text { sengketa }\end{array}$ \\
\hline 4. & $\begin{array}{c}\text { ASEAN Ministerial } \\
\text { Meeting }\end{array}$ & $\begin{array}{c}\text { AMM ke-44 yang diselenggarakan di Bali 19 } \\
\text { Juli 2011, Pentingnya perdamaian dan stabilitas } \\
\text { LCS. Penyelesaian sengketa secara damai } \\
\text { menurut hukum internasional }\end{array}$ & $\begin{array}{c}\text { Belum mampu } \\
\text { menyelesaikan } \\
\text { sengketa }\end{array}$ \\
\hline 5. & $\begin{array}{c}\text { Declaration on the } \\
\text { Conduct } \text { of Parties } \\
\text { in the South China } \\
\text { Sea, 2002 }\end{array}$ & $\begin{array}{c}\text { Dokumen politik yang tidak memiliki kekuatan } \\
\text { hukum mengikat dimana pihak-pihak yang } \\
\text { terlibat sengketa melanggar kesepakatan yang } \\
\text { ada tidak terdapat sanksi yang dapat diterapkan } \\
\text { kepada pihak pelanggar }\end{array}$ & $\begin{array}{c}\text { Belum mampu } \\
\text { menyelesaikan } \\
\text { sengketa }\end{array}$ \\
\hline 6. & $\begin{array}{c}\text { Gugatan Filipina } \\
\text { atas Tiongkok ke } \\
\text { Mahkamah }\end{array}$ & $\begin{array}{c}\text { Klaim Cina atas wilayah perairan itu tidak } \\
\text { sesuai dengan Konvensi PBB tahun 1982 } \\
\text { tentang Hukum Laut sehingga seharusnya }\end{array}$ & $\begin{array}{c}\text { Belum mampu } \\
\text { menyelesaikan } \\
\text { sengketa }\end{array}$ \\
\hline
\end{tabular}

13 ibid

14 http://internasional.metrotvnews.com/read/2015/10/29/445737/asean-kebut-coc-demi-atasi-konflik-lautchina-selatan diakses pada 29 November 2015 


\begin{tabular}{|c|c|c|c|}
\hline & Internasional & dinyatakan tidak sah & \\
\hline 7. & $\begin{array}{c}\text { Code of Conduct } \\
\text { in the South China } \\
\text { Sea }\end{array}$ & $\begin{array}{c}\text { COC merupakan pengimplementasian dari } \\
\text { DOC, COC disusun sebagai dokumen yang } \\
\text { mengatur tingkah laku negara-negara di } \\
\text { wilayah LCS }\end{array}$ & $\begin{array}{c}\text { Tahap } \\
\text { Perumusan }\end{array}$ \\
\hline
\end{tabular}

Sumber : Bahan hukum sekunder yang telah diolah penulis

Perselisihan di dalam LCS memang seyogyanya menjadi urgensi, bukan hanya para negara yang bersengketa di dalamnya, tetapi semua negara termasuk Indonesia. Mengingat keberadaan LCS sebagai jalur perdagangan sibuk, yang digunakan sebagai jalur perniagaan antar-negara yang dimana perniagaan merupakan salah satu penopang perekonomian sebuah negara. Dan juga mengingat banyak kepentingan akan beberapa kepulauan di LCS oleh negara di sekitarnya. Untuk itu perlu adanya upaya dari Indonesia yang merupakan poros maritim serta salah satu negara yang berpengaruh dan berperan aktif dalam ASEAN, agar tewujudnya harapan akan terselesainya perselisihan antar negera di LCS. Sehingga terciptanya perdamaian di wilayah LCS.

Berdasarkan latar belakang yang telah diuraikan tersebut maka, dalam penelitian ini yang menjadi rumusan masalah adalah :

1. Apakah urgensi Indonesia dalam penyelesaian sengketa di dalam wilayah LCS ?

2. Apa bentuk diplomasi yang sesuai dalam penyelesaian sengketa di wilayah LCS ?

\section{B. Pembahasan}

\section{Urgensi Indonesia dalam Penyelesaian Sengketa di dalam Wilayah Laut Cina Selatan.}

Keamanan LCS merupakan isu strategis yang dinamis dan tumbuh bersama dengan kemajuan kawasan Asia Pasifik. Kondisi yang sebenarnya saat ini menunjukkan bahwa kawasan LCS menjadi semakin penting, baik dari sisi letak geografis, ekonomi, politik dan pertahanan keamanan $^{15}$. Isu keamanan tersebut yang terus berkembang hingga saat ini dapat dikatakan belum terselesaikan, saling klaim antar negara di wilayah LCS yang melibatkan 5 negara ASEAN, Claimant States yang terdiri dari Malaysia, Philipina, Vietnam, Brunei dan non Claimant State yakni Indonesia.

15 Michael W. Guillot, "Strategic Leadership: Defining the Challenge", Air and Space Journal, MAXWEL AFB: Winter 2003, Vol. 17, 1554, hlm 3, dalam Yudho, Analisis Mengapa Pengembangan Postur Pertahanan Indonesia Tidak Merefleksi Perubahan Lingkungan Strategis di Kawasan Asia Tenggara Periode 2001-2004, UI Press, Jakarta, 2010, 


\section{Gambar 2.}

\section{Peta Resmi Republik Rakyat Tiongkok dalam PBB ${ }^{16}$}

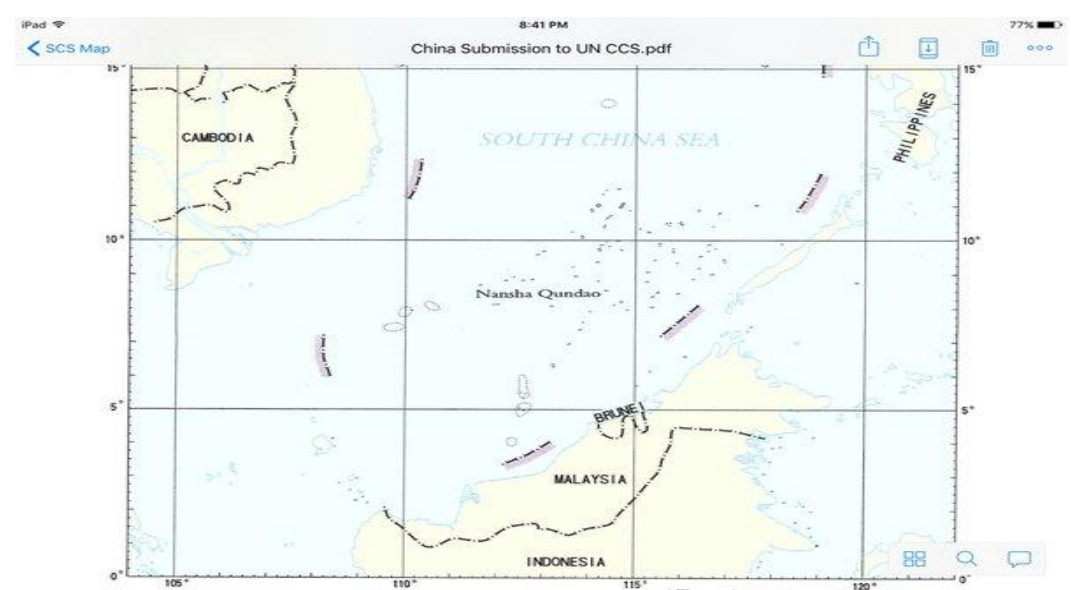

Jika dilihat dari peta di atas, tampak di Kepulauan Natuna tidak ada garis yang membatasi sejauh mana klaim Tiongkok. dikarenakan garis klaim tersebut merupakan garis imajiner berbagai sumber memperkirakan garis itu berada sekitar Zona Ekonomi Esklusif yang selanjutnya disebut ZEE wilayah Kepulauan Natuna ${ }^{17}$.

Kepulauan Natuna merupakan kepulauan paling utara di selat Karimata, Natuna berbatasan utara dengan Vietnam dan Kamboja, sebelah selatan berbatasan dengan Sumatera Selatan dan Jambi, sebelah barat dengan Singapura, Malaysia, Riau dan sebelah timur berbatasan dengan Kalimantan Barat. dengan posisi tersebut terlihat bahwasanya letak kepulauan Natuna berada di selatan LCS.

Belum adanya kejelasan dari garis klaim nine dash line yang menjadi pemasalahan di Laut Cina Selatan, dan sikap pemerintah Tiongkok yang dirasa sengaja menghindari diskusi publik terkait isu ZEE. hal ini memicu keraguan pemerintah Indonesia atas sikap Tiongkok terhadap Kepulauan Natuna ${ }^{18}$.

Zona Ekonomi Eksklusif yang menjadi urgensi Indonesia mengingat belum ada kejelasan dari pihak Tiongkok mengenai nine dash line yang di beritakan menyentuh perairan Natuna, ZEE sendiri merupakan suatu daerah di luar dan berdampingan dengan laut teritorial, yang tunduk pada rejim hukum khusus yang ditetapkan berdasarkan mana hak-hak dan yurisdiksi negara pantai dan hak-hak serta kebebasan-kebebasan negara lain, diatur oleh ketentuan-ketentuan yang relevan Konvensi UNCLOS ${ }^{19}$ untuk lebar ZEE dijelaskan bahwa tidak boleh melebihi 200 mil laut dari garis pangkal darimana lebar laut teritorial diukur ${ }^{20}$.

\footnotetext{
16 https://twitter.com/damos_agusman/status/668426498647289856/photo/1 diakses pada 11 Desember 2015

$17 \mathrm{http} / /$ dunia.tempo.co/read/news/2015/11/21/118720925/cina-akui-hak-indonesia-atas-kepulauan-natuna diakses pada 11 Desember 2015

18 http://www.suara-kita.com/2015/11/china-akhirnya-akui-pulau-natuna-milik.html diakses pada 12 Desember 2015

19 Pasal 55 UNCLOS 1982

20 Pasal 57 UNCLOS 1982
} 
Terdapat beberapa hak yang dimiliki negara pada ZEE antara lain :

a. Hak-hak berdaulat untuk keperluan eksplorasi dan eksploitasi, konservasi dan pengelolaan sumber kekayaan alam, baik hayati maupun non-hayati, dari perairan di atas dasar laut dan dari dasar laut dan tanah di bawahnya dan berkenaan dengan kegiatan lain untuk keperluan eksplorasi dan eksploitasi ekonomi zona tersebut, seperti produksi energi dari air, arus dan angin

b. Yurisdiksi sebagaimana ditentukan dalam ketentuan yang relevan dalam Konvensi ini berkenaan dengan :

1) pembuatan dan pemakaian pulau buatan, instalasi dan bangunan

2) riset ilmiah kelautan

3) perlindungan dan pelestarian lingkungan laut ${ }^{21}$

Beberapa sumber mengatakan bahwasanya nine dash line Tiongkok menyentuh perairan kepulauan Natuna, hal ini yang menjadi menjadi kecemasan bagi Indonesia mengingat potensi yang terdapat di wilayah tersebut. Dengan masuknya nine dash line di wilayah ZEE kepulauan Natuna maka menganggu hak berdaulat Indonesia, seperti yang telah dijelaskan di bab sebelumnya, bahwa dalam ZEE terdapat hak untuk keperluan eksplorasi dan eksploitasi, konservasi dan pengelolaan sumber kekayaan alam, baik hayati maupun non-hayati, dari perairan di atas dasar laut dan dari dasar laut dan tanah di bawahnya dan berkenaan dengan kegiatan lain untuk keperluan eksplorasi dan eksploitasi ekonomi zona tersebut, seperti produksi energi dari air, arus dan angin.

UNCLOS 1982 mengatur mengenai hak-hak dan kewajiban negara lain pada ZEE, dikatakan bahwa negara pantai dalam melaksanakan hak-hak dan kewajibanya, menurut UNCLOS 1982 pada ZEE haruslah memperhatikan hak-hak dan kewajiban negara lain ${ }^{22}$

Diatur pula mengenai hak-hak negara lain dalam ZEE antara lain :

a. Kebebasan pelayaran dan penerbangan

b. Kebebasan meletakkan kabel-kabel di bawah laut dan pipa-pipa dan pemakaian laut lainya yang dibenarkan secara internasional dalam kaitan dengan hal-hal tersebut, seperti hal-hal yang bertalian dengan operasi kapal, pesawat terbang, kabel-kabel laut dan pipa-pipa ${ }^{23}$

Dijelaskan pula bahwa negara-negara harus memperhatikan sebagaimana mestinya hakhak dan kewajiban Negara dalam hal ini Indonesia , dan harus mentaati peraturan perundangundangan yang ditetapkan oleh Negara, sesuai dengan ketentuan UNCLOS 1982 dan peraturan hukum internsional $^{24}$

Pasal 56 UNCLOS 1982

Pasal 56 ayat 2 UNCLOS 1982

Pasal 58 ayat 1 UNCLOS 1982

Pasal 58 ayat 3 UNCLOS 1982 
Indonesia yang terdaftar sebagai negara yang ikut menandatangani UNCLOS ${ }^{25} 1982$ mempunyai peran penting dalam penyelesaian LCS ditinjau dari kepentingan Indonesia di dalam negeri maupun di luar negeri. Merespon kasus sengeketa LCS, yang memungkinkan Indonesia sendiri masuk dalam sengketa di wilayah LCS dikarenakan garis imajiner atau nine dash line klaim tiongkok atas LCS masuk dalam wilayah teritorial laut Indonesia lebih tepatnya di wilayah ZEE Negara Kesatuan Republik Indonesia (NKRI), itu artinya Indonesia berpotensi sebagai negara yang ikut bersengketa.

Indonesia mempunyai peran yang sangat signifikan dalam penyelesaian LCS ini. pertama, Indonesia harus selalu mewaspadai situasi keamanan LCS yang sering dijadikan sengketa oleh beberapa negara di kawasan konflik di kawasan akan mempengaruhi kondisi keamanan, karena secara geografis letak Indonesia berbatasan langsung dengan negara-negara yang terlibat sengketa. Konflik juga akan mempengaruhi secara ekonomi, karena selain letak Indonesia yang secara geografis sangat dekat dengan Zona Ekonomi Eksklusif Indonesia, wilayah itu juga salah satu jalur lintas ekonomi internasional, dimana ekspor impor Indonesia melewati jalur itu. ${ }^{26}$ Kedua, Indonesia yang menjadi bagian dari masyarakat internasional, merasa perlu dan segera menentukan jalan terbaik bagi penyelesaian masalah LCS. Karena dengan cara inilah Indonesia dapat menunjukan partisipasinya dalam menjaga perdamaian dunia yang dimulai dengan menciptakan perdamaian di dalam negeri dan di kawasan. ${ }^{27}$

Untuk itu Indonesia sebagai negara yang berdaulat dan sekaligus bagian dari masyarakat internasional sudah selayaknya ikut menjaga perdamaian dalam negeri maupun di luar negeri, hal itu sebagaimana diamanatkan dalam pembukaan Undang-Undang Dasar Negara Republik Indonesia 1945 (UUD NRI 1945) alinea IV di pembukaan UUD NRI 1945 dikatakan, untuk memajukan kesejahteraan umum, mencerdaskan kehidupan bangsa, dan ikut melaksanakan ketertiban dunia yang berdasarkan kemerdekaan, perdamaian abadi dan keadilan sosial. Karena sudah di amanatkan dalam pembukaan UUD NRI 1945, Indonesia mempunyai alasan kuat ikut mancari jalan keluar dalam hal penyelesaian sengketa LCS.

\section{Bentuk Diplomasi yang Sesuai dalam Penyelesaian Sengketa di Wilayah Laut Cina Selatan.}

Upaya yang telah dilakukan oleh negara-negara yang bersengketa dalam LCS, hingga sampai saat ini belum menemui hasil yang dapat dikatakan memuaskan bagi negara-negara tersebut, berbagai macam usaha yang telah dilakukan memiliki kelemahan sendiri seperti upaya Declaration on the Conduct of Parties in the South China Sea, 2002 yang selanjutnya disebut DOC, dalam hal upaya penyelesaian sengketa LCS yang secara substansi merupakan dokumen politik yang tidak memiliki kekuatan hukum mengikat dimana pihak-pihak yang terlibat sengketa melanggar kesepakatan yang ada tidak terdapat sanksi yang dapat diterapkan

25 Dalam ASEAN negara yang tidak meratifikasi UNCLOS 1982 hanya Cambodja dalam website United Nations Treaty Collection

26 I Nyoman Sudira, "Konflik Laut Cina Selatan dan Politik Luar Negeri Indonesia ke Amerika dan Eropa", Jurnal Ilmiah Hubungan Internasional, Vol. 10 No. 2, 2014, hlm. 152

27 Brown, Michael E, 1996 The International Dimention of Internal Conflict, CSIA Studies in International Security. The MIT Press, Cambridge, London, hlm. 9 
kepada pihak pelanggar. Sampai dengan upaya yang disebut COC yang selanjutnya disebut Code of Conduct in the South China Sea yang secara substansi merupakan pengimplementasian dari $D O C, C O C$ disusun sebagai dokumen yang mengatur tingkah laku negara-negara di wilayah LCS yang hingga kini masih dalam tahap pembahasan.

Menurut Joseph Nye Jr. soft power merupakan sebuah konsep yang dikembangkan untuk menggambarkan kemampuan suatu negara untuk mengajak bekerjasama negara lain tanpa menggunakan hard power yaitu senjata maupun materi ${ }^{28}$. Ada beberapa hal yang menopang terciptanya soft power antara lain : Kebudayaan, Nilai-nilai politik, Diplomasi ${ }^{29}$

Diplomasi merupakan upaya yang harus dilakukan dalam hal penyelesaian sengketa LCS, mengingat apa yang disampaikan mengenai sengketa LCS tidak dapat dilakukan dengan kekuatan militer. karena jika di analisa mengenai kekuatan militer yang dimiliki oleh 5 negara yaitu, 4 Claimant States yang terdiri dari Malaysia, Philipina, Vietnam, Brunei dan 1 non Claimant State yakni Indonesia, yang meskipun anggaran pertahanan dan kekuatan militer mereka di gabung, tetap masih terjadi ketidak seimbangan kekuatan, ini bisa lihat dari besarnya jumlah anggaran pertahanan, alutsista serta jumlah prajurit yang dimana Tiongkok lebih besar dalam segala hal.

Dikatakan bahwa penyelesaian secara hukum dan upaya Politik serta diplomatik merupakan cara yang paling tepat saat ini untuk sengketa di LCS, Joseph Nye mengatakan bahwa bentuk kebijakan pemerintah dalam soft power meliputi : Public Diplomacy, Bilateral, Multilateral diplomacy.

Pertama yang harus dilakukan dalam LCS adalah Klarifikasi Nine dash line, hal itu menjadi hal yang penting untuk diklarifikasi mengingat hal tersebut merupakan rentetan dari peta baru yang dikeluarkan oleh Tiongok. Menurut hemat kami klarifikasi Nine dash line perlu segera dilakukan dengan cara : 1. Klarifikasi dimintakan kepada Tiongkok secara langsung; 2. Klarifikasi dimintakan kepada Tribunal ${ }^{30}$

Permintaan klarifikasi dimohonkan kepada Tribunal didasarkan pada Lampiran VI, Lembaran Of The International Majelis Hukum Laut, Pasal 31 mengenai Permintaan untuk campur :

a. Negara Pihak harus mempertimbangkan bahwa ia memiliki kepentingan yang bersifat hukum yang mungkin akan terpengaruh oleh keputusan dalam suatu sengketa, hal itu dapat mengajukan permintaan kepada Majelis yang akan diizinkan untuk campur tangan.

b. Itu akan bagi Majelis untuk memutuskan permintaan ini.

c. Jika permintaan untuk campur tangan dikabulkan, keputusan Majelis dalam sehubungan dengan sengketa akan mengikat Negara Pihak yang campur tangan

28 Joseph S. Nye Jr., Soft Power: The Means to Success in World Politics, PublicAffairs, New York, 2004, hlm. 1 .

29 Ibid. hlm 11

30 Boer Mauna, Hukum Internasional, Pengertian peranan fungsi dalam era ekonomi global, Alumni, Bandung, 2000, hlm.420 "Tribunal dibentuk tahun 1996 di Hamburg, Jerman. Yang bertujuan menyelesaikan sengketa-sengketa yang berhubungan dengan interpretasi dan pelaksanaan UNCLOS”. 
dalam sejauh yang berhubungan dengan hal-hal yang menghasilkan bahwa Negara Pihak campur.

ASEAN mempunyai peran yang cukup signifikan dalam menyelesaikan kasus sengketa LCS, berangkat dari ASEAN adalah organisasi induk negara-negara di kawasan Asia Tenggara. ASEAN perlu memberikan wadah demi tercapainya rasa aman dan nyaman negaranegara didalamnya. Untuk membahas permasalahan yang terjadi di LCS, Konferensi Tingkat Tinggi yang selanjutnya disingkat KTT pernah dilaksanakan beberapa kali dari tahun 1997 hingga yang terakhir KTT ASEAN-Tiongkok ke-13, pada 29 Oktober 2010. ASEANTiongkok Pertama di Kuala Lumpur pada 16 Desember 1997 tersebut menghasilkan Joint Statement on ASEAN-China pada paragraf 8 yang berbunyi.

Recognizing that the maintenance of regional peace and stability served the interests of all parties, they undertook to resolve their differences or disputes through peaceful means, without resorting to the threat or use of force, The parties concerned agreed to resolve their disputes in the South China Sea through friendly consultations and negotiations in accordance with universally recognized international law, including the 1982 UN Convention on the Law of the Sea. While continuing efforts to find solutions, they agreed to explore ways for cooperation in the areas concerned. In the interest of promoting peace and stability as well as enhancing mutual confidence in the region, the parties concerned agreed to continue to exercise self-restraint and handle relevant differences in a cool and constructive manner. They further agreed not to allow existing differences to hamper the development of friendly relations and cooperation ${ }^{31}$.

Pernyataan tersebut menyatakan bahwa Tiongkok mendukung upaya-upaya ASEAN dan mengadakan diskusi terbuka dengan negara-negara yang berkepentingan, serta sepakat agar masalah LCS diselesaikan melalui perundingan berdasarkan hukum internasional termasuk UNCLOS dan melakukan upaya kerjasama di wilayah sengketa ${ }^{32}$ dan dalam KTT tersebut membahas apa yang diinginkan Tiongkok dalam penyelesaian sengketa LCS, yakni dengan bilateral. Dapat dikatakan demikian terlihat dari sikap Tiongkok yang secara langsung terkesan tidak mengindahkan gugatan Filipina ke Mahkamah Internasional dan lebih cenderung menginginkan perselisihan tersebut diselesaikan dengan dialog bilateral $^{33}$

Negara-negara yang berkonflik melakukan pembuktian berdasarkan data-data mengenai daerah yang mereka klaim, beserta sumberdaya laut didalamnya. Maksud dari meneliti potensi sumber daya laut adalah ketika diketahui bahwa terdapat potensi-potensi yang bisa dijadikan bahan negoisasi bagi negara yang saling klaim untuk bekerjasama dalam hal sumber daya laut tersebut. Dengan dialog bilateral ini diharapkan nantinya mampu memberikan win-

31 Joint Statement of the Meeting of Heads of State/Government of the Member States of ASEAN and the President of the People's Republic of China, www.asean.org/news/item/joint-statement-of-the-meeting-ofheads-of-stategovernment-of-the-member-states-of-asean-and-the-president-of-the-people-s-republic-ofchina-kuala-lumpur-malaysia-16-december-1997 diakses pada 16 Desember 2015

32 Termsak Chalermpalanupap, The South China Sea and ASEAN, hlm 6.

33 Tiongkok Tegaskan Sikapnya Terhadap Filipina Terkait Laut Cina Selatan, dalam http://www.theglobalreview.com/content_detail.php?lang=id\&id=16760\&type=105\#.VnFvGtJ97Dc diakses pada 15 Desember 2015 
win solution atau bahkan bekerja sama, hal ini yang kami sebut sumber daya kelautan lintas batas, dengan catatan kerjasama dilakukan dengan tanpa merugikan salah-satu pihak terkait kedaulatanya. Mengingat konferensi ini bertujuan untuk menyelesaikan sengketa di LCS. Kemudian hasil dari dialog kerjasama bilateral tersebut dijadikan dokumen hukum yang mengikat bagi para pihak $^{34}$, hal ini menjadi penting mengingat kelemahan dari Declaration on the Conduct of Parties in the South China Sea yang selanjutnya disingkat DOC. Yang secara substansi DOC hanya merupakan dokumen politik yang tidak memiliki kekuatan hukum mengikat dimana pihak-pihak yang terlibat sengketa, melanggar kesepakatan yang ada tidak terdapat sanksi yang dapat diterapkan kepada pihak pelanggar, Selama ini dokumen DOC hanya berfungsi untuk memberi batasan-batasan moral bagi para pihak yang terkait. Tetapi dokumen DOC setidak-tidaknya telah berperan sebagai referensi ketika muncul masalah atau terjadi ketegangan dan juga berperan sebagai dasar untuk negosiasi mengenai penyusunan dokumen code of conduct yang selanjutnya disingkat COC. Kemudian dalam hal lalu-lintas perniagaan, pelayaran dan semua aktivitas yang di wilayah LCS diatur dengan $\mathrm{COC}$, yang disusun sebagai dokumen yang mengatur tingkah laku negara-negara di wilayah LCS yang sampai saat ini dalam tahap perumusan.

Penyelesaian sengketa LCS dengan diplomasi soft power asimetris dirasa sangat efektif mengingat posisi tawar dari negara-negara yang saling berkonflik tidak sepadan. Sebagaimana dijelaskan di bab sebelumnya mengenai diplomasi yang merupakan upaya yang harus dilaukan dalam penyelesaian sengketa. Sedangkan soft power merupakan sebuah konsep yang dikembangkan untuk menggambarkan kemampuan suatu negara untuk mengajak bekerjasama negara lain tanpa menggunakan hard power yaitu senjata ataupun materi. Pengertian Asimetris sendiri kami ambil dari buku Asymmetric Warfare yang berarti perang asimetris.

Asymmetric Warfare is violent action undertaken by 'the have-nots' against the 'haves' whereby the have-nots, be they state or sub-state actors, seek to generate profound effects -at all level of warfare (however defined), from the tactical to the strategic - by employing their own specific relative advantages against the vulnerability of much stronger that opponents ${ }^{35}$

Dapat dikatakan bahwa peperangan asimetris sebagai aksi kekerasan yang dilakukan oleh Si miskin (pihak yang lemah) terhadap Si Kaya (pihak yang kuat), baik sebagai Negara atau sub-negara. Peperangan ini sesungguhnya telah berlangsung dengan cara yang non konvensional. Secara sederhana, jenis peperangan ini merupakan pertikaian antara dua kekuatan atau lebih dengan tidak menggunakan mesin perang dan persenjataan yang canggih $^{36}$. Dari pernyataan tersebut dapat di lihat dari kemampuan negara-negara yang saling

34 Dalam sengketa LCS dilakukan KTT ASEAN + Tiongkok = Perjanjian para pihak (dokumen hukum) /Treaty Of Contract(perjanjian khusus/perjanjian tertutup), yang merupakan perjanjian yang hanya melahirkan suatu kaidah hukum atau hak-hak dan kewajiban yang hanya berlaku pada pihak-pihak yang bersangkutan saja, tetapi traktat ini juga dapat mengikat pihak-pihak lain apabila syarat-syaratnya terpenuhi dan setelah melalui proses-proses yang ditentukan bagi terbentuknya sebuah kebiasaan. Dalam I.A Shearer, Starke's International Law, London : Butterworth,1994,hlm.39-40. dalam Jawahir Thontowi \& Pranoto Iskandar, Hukum Internasional Kontemporer, PT. Refika Aditama, Bandung,2006, hlm. 59

35 Jurnal Intelijen Indonesia, Edisi September 2015, hlm 26

36 Ibid 
bersengketa di LCS, disana melibatkan, 4 Claimant States yang terdiri dari Malaysia, Philipina, Vietnam, Brunei dan 1 non Claimant State yakni Indonesia, yang meskipun anggaran pertahanan dan kekuatan militer mereka di gabung, tetap masih terjadi ketidak seimbangan kekuatan, ini bisa lihat dari besarnya jumlah anggaran pertahanan, alutsista serta jumlah prajurit yang dimana Tiongkok lebih besar dalam segala hal. Jadi perlu adanya sebuah penyelesaian sengketa LCS dengan menggunakan model win-win solution atau yang juga dikenal dalam falsafah jawa " menang tanpo ngasorake" yang jika diartikan kedalam bahasa Indonesia, menang tanpa mempermalukan. Hal ini dapat dilihat dalam diplomasi soft power asimetris dengan memperhatikan beberapa hal :

a. Meninta klarifikasi Nine Dash Line dengan 2 metode yaitu:

1) Klarifikasi oleh Tiongkok

2) Klarifikasi oleh Tribunal

b. Menggunakan KTT sebagai forum diskusi antara ASEAN dan Tiongkok, hal ini memperhatikan kepentingan ASEAN yang menginginkan penyelesaian dengan forum multilateral

c. Menggunakan dialog Bilateral, hal ini memperhatikan keinginan Tiongkok atas penyelesaian klaim di LCS

d. Belajar dari kelemahan DOC yang tidak mengikat para pihak hanya merupakan dokumen politik yang tidak memiliki kekuatan hukum mengikat dan tidak terdapat sanksi yang dapat diterapkan kepada pihak pelanggar.

e. Menggunakan $\mathrm{COC}$, yang disusun sebagai dokumen yang mengatur tingkah laku negara-negara di wilayah LCS yang sampai saat ini dalam tahap perumusan.

Diharapkan dengan diplomasi soft power asimetris yang memperhatikan kepentingankepentingan baik negara maupun organisasi nantinya mampu menjadi alternatif penyelesaian sengketa LCS yang berlarut-larut, dengan catatan win-win solution dapat dirasakan secara langsung bagi mereka yang bersengketa, dan menang tanpo ngasorake tidak merugikan bagi negara-negara yang turut bersengketa di dalamnya.

\section{Penutup}

1. Urgensi Indonesia turut campur dalam Laut Cina Selatan selain karena terdapat beberapa hak yang harus diperhatikan di ZEE, serta dalam pembukaan Undang-Undang Dasar Negara Kesatuan Republik Indonesia tahun 1945 alinea ke IV mengatakan bahwa untuk memajukan kesejahteraan umum, mencerdaskan kehidupan bangsa dan ikut melaksanakan ketertiban dunia.

2. Perlu adanya suatu upaya dalam sengketa Laut Cina Selatan, dengan cara damai tanpa ada kekerasan yaitu diplomasi soft power asimetris, hasil dari perundingan tersebut diterbitkan dokumen hukum yang bersifat mengikat pihak-pihak. Lalu-lintas perniagaan, pelayaran serta aktivitas di Laut Cina Selatan menggunakan $C O C$, yang didalamnya mengatur tingkah laku dalam wilayah Laut Cina Selatan 


\section{Daftar Pustaka}

\section{Buku :}

A.A, Perwita., dan Y. M., Yani, Pengantar Ilmu Hubungan Internasional, PT Remaja Rosdakarya, Bandung, 2005

Bambang Cipto, Hubungan Internasional di Asia Tenggara, Pustaka Pelajar, Yogyakarta, 2007

Boer Mauna, Hukum Internasional, Pengertian peranan fungsi dalam era ekonomi global, Alumni, Bandung, 2000

Brown, Michael E, The International Dimention of Internal Conflict: CSIA Studies in International Security. The MIT Press, Cambridge, London, 1996

Cornelis Kowaas, Dewaruci: Pelayaran Pertama Menaklukan Tujuh Samudra, kompass, November 2010

Jahari Thontowi dan Pranoto Iskandar, Hukum Internasional Kontemporer, Refika Aditama, Bandung, 2006

Joseph S. Nye Jr., Soft Power: The Means to Success in World Politics, PublicAffairs, New York, 2004

Mills, Kurt, Human Rights in the Emerging Global Order : A New Sovereighty?, Palgrave Macmillan, UK, 1998.

Mochtar Kusumaatmaja, Pengantar Hukum Internasional, Bina Cipta, Bandung, 1976

Peter Mahmud Marzuki, Penelitian Hukum, Prenada Media Group, Jakarta, 2012

Rosenau, J.N., World Politics; an introduction. The Free Press, New York, 1976

Syamsumar Dam, Politik Kelautan, Bumi Aksara, Jakarta, 2010

Yudho, Analisis Mengapa Pengembangan Postur Pertahanan Indonesia Tidak Merefleksi Perubahan Lingkungan Strategis di Kawasan Asia Tenggara Periode 2001-2004, UI Press, Jakarta, 2010

\section{Jurnal dan E-Jurnal :}

I Nyoman Sudira, "Konflik Laut Cina Selatan dan Politik Luar Negeri Indonesia ke Amerika dan Eropa", Jurnal Ilmiah Hubungan Internasional, Vol. 10 No. 2, 2014

Jurnal Pertahanan ,South Cina Sea Maritime Security: Challenges And Oppurtunities, Dadang Sobar Wirasuta

Kementerian Luar Negeri Republik Indonesia, 2010, Pertemuan Kelompok Ahli (PKA), "Perkembangan di Laut Cina Selatan dan Dampaknya bagi Stabilitas Politik dan Keamanan di Kawasan Asia Pasifik: Penguatan Posisi dan Strategi RI, dalam 
http://www.kemlu.go.id, diunduh pada 7 Juli 2011 dalam Jurnal Pertahanan ,South Cina Sea Maritime Security: Challenges And Oppurtunities, Dadang Sobar Wirasuta Jurnal Intelijen Indonesia, Edisi September 2015

Klaus Krispendoff, 1993, Analisis Isi Pengantar Dan Teori Metodologi, Rajawali Press, Jakarta, hlm15 dalam http://digilib.uinsby.ac.ic/7528/6/bab\%203.pdf diakses pada: 4 September 2015

Laksamana TNI (Purn) Achmad Sucipto, "Bagaimana Kita Memandang Laut Cina Selatan”, Jalasena, Edisi III/2013 dalam Dadang Sobar Wirasuta, South Cina Sea Maritime Security Challenges And Oppurtunities

Michael W. Guillot, "Strategic Leadership: Defining the Challenge”, Air band Space Journal, MAXWEL AFB: Vol. 17, 1554, Winter 2003,

Pidato Yap Thiam Hien, "Preface : Law,State, and Civil Society in Indonesia, dalam Arief Budiman (ed.) State and Civil Society in Indonesia", Monash Papers on Southeast Asia No.22, 1990.

Simela Victor Muhammad, "Kepentingan China dan Posisi ASEAN dalam Sengketa Laut China Selatan”, Info Singkat Hubungan Internasional, Vol. IV No. 08, April 2012)

\section{Internet:}

www.tnial.mil.id/tabid/79/articleType/ArticleView/articleId/16930/Default.aspx, diakses pada 28 November 2015

internasional.metrotvnews.com/read/2015/10/29/445737/asean-kebut-coc-demi-atasi-konfliklaut-china-selatan diakses pada 29 November 2015

www.anneahira.com/laut-cina-selatan.htm l, diakses pada tanggal 28 November 2015

internasional.metrotvnews.com/read/2015/10/30/185779/tiongkok-as-didesak-atasi-klaimlaut-china-selatan-di-p diakses pada 28 November 2015

Bentuk Perjanjian, treaty.kemlu.go.id/index.php/treaty/download/1569, diakses pada 5 November 2015

dunia.tempo.co/read/news/2015/11/21/118720925/cina-akui-hak-indonesia-atas-kepulauannatuna, diakses pada 11 Desember 2015

Joint Statement of the Meeting of Heads of State/Government of the Member States ofASEAN and the President of the People's Republic of China, www.asean.org/news/ item/joint-statement-of-the-meeting-of-heads-of-stategovernment-of-the-member-statesof-asean-and-the-president-of-the-people-s-republic-of-china-kuala-lumpur-malaysia16-december-1997, diakses pada 16 Desember 2015

Tiongkok Tegaskan Sikapnya Terhadap Filipina Terkait Laut Cina Selatan, dalam 
http://www.theglobalreview.com/content_detail.php?lang=id\&id=16760\&type=105\#.VnFvGt J97Dc diakses pada 15 Desember 2015

nationalgeographic.co.id/berita/2015/11/indonesia-minta-china-klarifikasi-atas-klaimkepulauan-natuna diakses pada 29 November 2015

www.suara-kita.com/2015/11/china-akhirnya-akui-pulau-natuna-milik.html, diakses pada 12 Desember 2015

\section{Majalah :}

MAJALAH TANNAS Edisi 94,2012 hlm. 38 